\title{
O jornalismo \\ e os professores: \\ os jogos de imagens
}

Katia Zanvettor Ferreira

Pesquisadora colaboradora junto ao Laboratório de Estudos Avançados em Jornalismo (Labjor), do Núcleo de Desenvolvimento da Criatividade (Nudecri/Unicamp) e professora do curso de Jornalismo da Universidade do Vale do Paraíba (Univap).

E-mail: katia.zanvettor@gmail.com

Resumo: Este trabalho pretende fazer uma reflexão acerca das intersecções entre o professor e o jornalismo, trazendo uma reconstrução das imagens do professor que predominam nas publicações dos jornais. A análise dos textos nos mostrou que um dos recursos utilizados pelo jornalismo para produzir uma imagem positiva de si é o apoio em um discurso de cientificidade, com base no uso de fontes de informação, que reforça a perspectiva de que seus discursos são representações objetivas da realidade. Outra conclusão a que chegamos foi que a imagem dos professores continua se constituindo sob uma perspectiva negativa, acrescida de um dado novo, que é a crescente proposição de exclusão dos professores e substituição desses profissionais por outros melhores, como saída para os problemas da educação. Neste artigo, pretendemos problematizar essas duas conclusões, apresentando em primeiro lugar os dados sobre as fontes de informação no jornalismo quando se trata de educação e, em segundo lugar, apresentar a análise dos textos jornalísticos e os sentidos construídos para o professor no jornal hoje.

Palavras-chave: professores; discurso jornalístico; ideologia.
Abstract: This paper aims to consider the intersections between teachers and journalism, reconstruction from what is published about teachers in the newspapers, the predominating images of this professional. The texts analysis showed thar one of the resources used by journalists to project a positive image of theirselves is the cientific discourse, based on information sources, which reinforces the perspective that their speeches are objectiv representations of reality. Another conclusion we reached was that the teacher's image is still under a negative perspective, added to it the increasing proposal of a substitution of these professionals as a resolution for the educational problems. In this paper we intend to analyse these two conclusions, firstly presenting data about the information sources use by journalism when it comes to education, and, secondly presenting the analysis of the texts and the senses constructed about teachers in the news nowadays.

Keywords: teachers; journalistic discourse; ideology.

\section{O JOGO DE ESPELHOS}

Este trabalho é um desdobramento da tese de doutorado defendida na Faculdade de Educação da Universidade de São Paulo (USP) que tem como 
1. PÊCHEUX, Michel; FUCHS, C. A propósito da análise automática do discurso: atualização e perspectivas. In: GADET, Françoise; HAK, Tony. Por uma análise automática do discurso: uma introdução à obra de $\mathrm{Mi}$ chel Pêcheux. Campinas: Editora da Unicamp, 2010.

2. CARMAGNANI, 2004; BARBARA e BEBER-SARDINHA, 2004; ROCHA, 2007; FERREIRA, 2002; e ANJOS, 2008. título: Quando o professor é notícia? Imagens de professor e imagens de jornalismo. $\mathrm{O}$ objetivo naquela investigação foi entender os discursos que permeiam as notícias sobre o professor e como esses discursos evidenciam imagens dos professores e também imagens de jornalismo. Para tanto, analisamos notícias relacionadas ao professor do ensino básico, publicadas entre janeiro de 2009 e janeiro de 2010 no jornal Folha de São Paulo, buscando depreender as imagens produzidas sobre este profissional.

Nosso referencial teórico se pautou no trabalho de Pêcheux ${ }^{1}$ sobre as Formações Imaginárias e Ideológicas. Usamos esse referencial porque defendemos que ainda que o texto jornalístico se esforce para apagar a sua inscrição discursiva, ele é, antes de tudo, uma produção de sentidos sobre o mundo. Essa perspectiva nos permitiu compreender que no jornalismo as notícias sobre os professores se materializam sempre em um processo de jogos de imagens, em que a construção de uma imagem negativa do professor se dá em contraponto à construção de uma imagem positiva do jornalismo.

A análise dos textos nos mostrou que um dos recursos utilizados pelo jornalismo para produzir uma imagem positiva de si é o apoio em um discurso de cientificidade, com base no uso de fontes de informação, que reforça a perspectiva de que seus discursos são representações objetivas da realidade. Outra conclusão a que chegamos foi que a imagem dos professores continua se constituindo sob uma perspectiva negativa, acrescida de um dado novo que é a crescente proposição de exclusão dos professores e substituição desses profissionais por outros melhores como saída para os problemas da educação.

Neste artigo, pretendemos problematizar essas duas conclusões, apresentando em primeiro lugar os dados sobre as fontes de informação no jornalismo quando se trata de educação e, em segundo lugar, apresentar a análise dos textos jornalísticos e os sentidos construídos para o professor no jornal hoje.

\section{O PROFESSOR NO JORNAL}

Infelizmente a constatação de que a imagem do professor de educação básica na mídia é pejorativa não parece ser uma novidade em se tratando de estudos em educação. Um levantamento bibliográfico no qual pudemos reunir estudos anteriores ${ }^{2}$ que apontam que a imagem do professor há algum tempo tem sido apresentada nos discursos jornalísticos, reportados em seus mais diversos suportes, associada a um sentido pejorativo. No geral, os trabalhos mostram que em textos jornalísticos os saberes e os modos de trabalho dessa categoria profissional são constantemente desqualificados e, muitas vezes, associados como causa da má qualidade da educação brasileira. Desses levantamentos observamos que a chamada "desqualificação do professor" na mídia está atrelada a temas que divulgam os "problemas da educação”, em geral a veiculação de notícias que apontam o professor como o verdadeiro culpado de toda a crise. Além disso, há repetição no modo de construir 
sentidos sobre o professor e que esse sujeito está excluído de se colocar, em tal discurso, como um agente de mudança.

Os trabalhos em geral investigam diferentes gêneros, mas há um importante interesse para o que é publicado em revistas, particularmente em revistas que cobrem exclusivamente a área de educação, particularmente a revista Nova Escola. A revista Nova Escola é uma publicação da Editora Abril e gerida pela fundação Victor Civitta, é mensal e tem como pauta, ou seja, seu principal interesse de cobertura são temas que vão da educação infantil ao ensino médio.

Em uma investigação sobre a revista Nova Escola ${ }^{3}$, por exemplo, na qual a pesquisadora analisou 48 exemplares da revista, publicados entre 2001 a 2004 observou-se a tendência pela construção negativa da imagem do professor. Analisando os "relatos de experiência" (relatos em que um professor-leitor escreve para a revista Nova Escola) e "experiências relatadas" (relatos em uma experiência de ensino de língua materna realizadas em sala de aula), a pesquisa identificou a divulgação ao leitor (professor) da importância de se copiar uma figura mítica: o professor ideal. Este trabalho aponta para duas tendências na divulgação desse modelo: uma de proposição e outra de imposição. Utilizando como metodologia a análise dos relatos - tanto de experiência como experiência relatada - a pesquisadora pode apontar a existência e a divulgação de um "modelo de professor ideal". Ou seja, apontou que, para a revista, o professor brasileiro precisa de um guia externo e este guia seria a própria revista. A investigação pode evidenciar ainda como um dos possíveis efeitos dessa divulgação ora propositiva, ora impositiva o favorecimento de uma postura de desresponsabilização por parte do professor em relação ao seu trabalho e a realização de atividades de ensino que não levam em conta a pluralidade de contextos educacionais no Brasil.

Numa perspectiva metodológica próxima encontramos outro trabalho intitulado A educação infantil representada: uma análise da revista Nova Escola (2005$-2007)^{4}$, no qual o pesquisador analisa as matérias publicadas na revista buscando depreender as representações da educação infantil veiculadas nesse periódico. O enfoque na pesquisa foi compreender como as diferentes correntes teóricas da educação infantil são representadas no periódico. De novo, a pesquisa mostra que há um "processo de segregação", enfrentado pelos docentes que não se enquadram no referencial proposto pela revista e, por outro lado, a revista se coloca como portadora de prescrições essenciais para o professor atingir a excelência.

Outro exemplo metodológico da investigação sobre o professor no jornal é a investigação empreendida por Barbara e Beber-Sardinha ${ }^{5}$, que analisou o subcorpus do Banco de Português ${ }^{6}$, na qual constam textos publicados tanto em revistas como em jornal e que também colabora para confirmar a exclusão do professor de ensino básico nestas fontes. Os pesquisadores trabalham com as perspectivas da Linguística de Corpus e da Linguística Sistêmico-funcional e defendem um melhor emprego dos computadores nas investigações de linguagem como uma forma de ampliar o universo de dados empíricos. Nesta pesquisa foram analisadas 223.731.280 palavras de textos de jornais e revistas
3. ROCHA, Andreza Roberta. Relatos de experiência publicados na revista Nova Escola (2001-2004): modelo de professora ideal. Dissertação de mestrado. Faculdade de Educação, Universidade de São Paulo, 2007.

4. ANJOS, Cleriston Izidro dos. A educação infantil representada: uma análise da revista Nova Escola (2005-2007). Dissertação de mestrado. Faculdade de Educação, Universidade de São Paulo, 2008.

5. BARBARA, L.; BERBERSARDINHA, T. Professor: a imagem projetada na imprensa. Ilha do Desterro. (UFSC), v. 17, n.2, 2004, p. 117-125.

6. Disponível em: <www4. pucsp.br/pos/lael>. 
utilizando o software WordSmith Tools - como contar palavras, identificar todas as ocorrências de um termo, classificar a ordem dos itens listados etc.). Dessas palavras, estudaram as sete ocorrências mais frequentes para o "lema" professor e, posteriormente, as sequências fixas de palavras que ocorrem próximas das palavras de busca. As conclusões que eles chegam por meio da pesquisa para as ocorrências do lema professor e suas realizações mais frequentes que aparecem na imprensa são:

- Professor e professora: são pessoas específicas, qualificadas por um título, ligadas à universidade, que dão opinião à imprensa.

- Professores: o termo corresponde a uma classe de trabalhadores, genérica, ligada a escola pública, associada a reivindicações e movimentos trabalhistas.

- Professoras: são pessoas específicas, de colégio.

A pesquisa conclui que há uma distinção no tratamento dado para os professores de universidades e para aqueles ligados ao ensino básico. Enquanto os primeiros são valorizados em sua individualidade, possuem voz e nome, os segundos, por sua vez, aparecem frequentemente sem nome, ligados à rede pública, salientando "pontos de sua formação que não são satisfatórios"7. O que se nota, portanto, como observam os pesquisadores, é a valorização dos professores pesquisadores da educação superior e o reforço do desprestígio da profissão docente enquanto categoria da educação básica.

As conclusões das pesquisas consultadas indicam que a depreciação do docente no discurso jornalístico não é novidade. O levantamento permitiu, em nossa própria pesquisa, observar que o que há de novo na imagem docente no jornalismo não é sua desqualificação, mas o modo como ela se dá. Assim, defendemos que o elemento novo nas escolhas jornalísticas para retratar o professor da educação básica não é a desqualificação, mas, sim, o modo de qualificar o professor, que ao fim desqualifica. Atualmente, a nosso ver, o discurso sobre essa categoria profissional se pauta numa perspectiva de "exclusão" dos professores que estão trabalhando e de substituição desses por outros, "melhores". Essa percepção só nos foi possível porque nos valemos da metodologia proposta por Barzotto $(1998)^{8}$ na qual em sua pesquisa observa que há um encadeamento de sentidos na construção dos discursos midiáticos.

Este autor, em seu estudo sobre a revista Realidade, observando a relação

7. BARBARA; BEBER-SARDINHA, idem, p. 125.

8. BARZOTTO, V. H. Leituras de revistas periódicas: forma, texto e discurso. Uma leitura da revista Realidade (19661976). Tese de doutorado. Campinas, Unicamp, 1998. entre os procedimentos de textualização e os modos de composição do suporte, observa que o discurso é resultado de um encadeamento de sentidos que o pesquisador pode inferir a partir da observação entre diferentes textos - elementos da diagramação, fotos e até propaganda. O encadeamento de sentido, contudo, para o autor ainda implica em uma posição do pesquisador, ou seja, as escolhas que o pesquisador faz sobre o modo de ler o material jornalístico influi também nessa produção de sentido. É importante frisar, no entanto, que no desenvolvimento dessa perspectiva metodológica o próprio autor ressalta 
que ainda que esse encadeamento de sentido seja resultado da implicação do leitor na relação que estabelece entre os sentidos dos textos lidos, ele (leitor) não está livre de algumas coerções próprias à produção do discurso. Entre elas, por exemplo:

“a) o modo como alguns elementos são inseridos no texto; b) a forma do veículo portador de textos; c) a forma que o texto assume no interior do suporte que o veicula; d) o movimento que a própria forma do veículo exige que o leitor faça no ato da leitura".

O autor propõe enfim, uma posição metodológica na análise das revistas que inclua a forma, texto e discurso ${ }^{10}$. Em nosso trabalho, trabalhamos essencialmente com a categoria de encadeamento de sentido que foi essencial para percebermos que um texto publicado em um jornal em determinada data não está necessariamente descolado do sentido de outro texto publicado em data posterior.

\section{ENCADEAMENTO DE SENTIDO}

Para contextualizar o que estamos dizendo trouxemos um exemplo de nossos próprios dados. Aqui apresentamos os títulos e as datas do corpus principal de pesquisa (Quadro 1).

\section{Quadro 1 - Corpus principal de análise ${ }^{11}$}

\begin{tabular}{c|c|l} 
No & Data de Publicação & \multicolumn{1}{l}{ Título do texto } \\
T1 & $03 / 02 / 2009$ & País forma cada vez menos professores. \\
\hline T2 & $03 / 02 / 2009$ & Para pedagogos, baixo salário e desprestígio explicam fenômeno \\
\hline T3 & $15 / 02 / 2009$ & Repitam a escola e os políticos. Não o aluno \\
\hline T4 & $17 / 02 / 2009$ & Socorro ao professor \\
\hline T5 & $28 / 05 / 2009$ & MEC quer tornar mais rigorosa a seleção dos futuros professores \\
\hline T6 & $28 / 05 / 2009$ & Com esse salário quem quer ser um professor? \\
\hline T7 & $18 / 08 / 2009$ & A pedagogia é uma jabuticaba? \\
\hline T8 & $04 / 10 / 2009$ & Para Unesco, situação do professor é crítica \\
\hline T9 & $04 / 10 / 2009$ & Estudos ligam boa educação a maior salário de professores \\
\hline T10 & $04 / 10 / 2009$ & Salário de professor sobe 18\% em 5 anos \\
\hline T11 & $22 / 10 / 2009$ & Risco é criar elite em meio a mal remunerados \\
\hline T12 & $23 / 10 / 2009$ & Prova terá peso maior para docente que disputar reajuste \\
\hline T13 & $24 / 10 / 2009$ & Valorização Docente \\
\hline T14 & $09 / 11 / 2009$ & 7 mitos na educação - Verdade ou Mentira \\
\hline
\end{tabular}

9. BARZOTTO, 2001, p. 146.

10. BARZOTTO, V. H. Olhares oblíquos sobre sentidos não muito dissimulados. In: GREGOLIN, Maria do Rosário; BARONAS, Roberto. (Org.) Análise do Discurso: as materialidades do sentido. São Carlos: Claraluz, 1998, pp. 205-217.

11. Textos publicados na versão impressa do jornal Folha de S.Paulo entre janeiro de 2009 e janeiro de 2010 e reunidos como corpus principal do trabalho. FERREIRA, Katia Zanvettor. Quando o professor é notícia? Imagens de professor e imagens do jornalismo. 2012. Tese de doutorado. Faculdade de Educação, Universidade de São Paulo, 2012. Disponível em: <www.teses.usp.br/teses/ disponiveis/48/48134/tde03082012-135123>. Acesso em: 23 out. 2012. 
comunicação \& educação • Ano XXI • número 2 • jul/dez 2016

\section{Quadro 2 - Principais trechos das 14 matérias selecionadas e analisadas}

\begin{tabular}{|c|c|}
\hline Texto & Trecho destacado \\
\hline $\mathrm{T} 1$ & $\begin{array}{l}\text { Pesquisadores da área de educação afirmam que a falta de interesse em ser } \\
\text { professor ocorre principalmente em razão dos baixos salários pagos no magistério } \\
\text { e à pouca valorização social da carreira. } \\
\text { Até mesmo escolas tradicionais reclamam das dificuldades para contratar professor. } \\
\text { O colégio Bandeirantes, de São Paulo, por exemplo, afirma que precisou criar um } \\
\text { programa para formar seus próprios ex-estudantes para as disciplinas mais críticas. }\end{array}$ \\
\hline T2 & $\begin{array}{l}\text { [...] não só o salário contribui para a baixa procura, "embora seja uma coisa } \\
\text { determinante", mas "a falta de estímulos para a profissão". }\end{array}$ \\
\hline T3 & $\begin{array}{l}\text { [...] existe uma dificuldade imensa de atrair talentos. Todo o resto é apenas } \\
\text { consequência, a começar dos cursos para formação de docentes. }\end{array}$ \\
\hline $\mathrm{T} 4$ & $\begin{array}{l}\text { Sem esse mínimo de garantias, cada vez menos talentos estarão dispostos a } \\
\text { seguir a carreira de professor, decisiva para reduzir a iniquidade social no país. }\end{array}$ \\
\hline T5 & $\begin{array}{l}\text { Diante das deficiências na formação de parcela expressiva dos professores, o } \\
\text { Ministério da Educação lança hoje um conjunto de medidas para, de um lado, } \\
\text { qualificar os que já estão em exercício e, de outro, tornar mais rigorosa a seleção } \\
\text { dos futuros docentes. }\end{array}$ \\
\hline T6 & $\begin{array}{l}\text { É verdade que há evidências empíricas de que salários maiores não significam } \\
\text { melhores notas de alunos nas avaliações do MEC. Mas esse é um dado que capta } \\
\text { apenas um efeito imediato. }\end{array}$ \\
\hline & $\begin{array}{l}\text { Sabe-se, a partir de um estudo da consultoria McKinsey, que os países com melhor } \\
\text { desempenho educacional são os que selecionam para suas escolas os profissionais } \\
\text { mais bem capacitados. Para isso, não há dúvida de que a remuneração é um fator } \\
\text { essencial. }\end{array}$ \\
\hline $\mathrm{T7}$ & $\begin{array}{l}\text { Basta copiar o que fazem as boas escolas: programas de ensino claros, } \\
\text { professores bem formados antes de entrar para o magistério, gestão escolar } \\
\text { eficiente e uso de pedagogias adequadas. }\end{array}$ \\
\hline T8 & $\begin{array}{l}\text { Os universitários de cursos de licenciatura e pedagogia vêm de famílias pobres, } \\
\text { com menor bagagem cultural. }\end{array}$ \\
\hline T9 & $\begin{array}{l}\text { Um estudo divulgado pela consultoria Mckinsey chegou a uma conclusão parecida } \\
\text { ao identificar como uma das características comuns em países bem avaliados no } \\
\text { PISA (Programa de Avaliação Internacional de Estudantes) o fato de a carreira ser } \\
\text { atrativa aos melhores profissionais que se formam no ensino médio. }\end{array}$ \\
\hline T10 & $\begin{array}{l}\text { Apesar desse aumento de renda do magistério, um relatório preparado pela } \\
\text { Unesco sobre a situação do professor no Brasil também destaca que os } \\
\text { diferenciais de salário em relação a outras profissões ainda são muito grandes, } \\
\text { o que contribui para diminuir a atratividade da carreira. }\end{array}$ \\
\hline T11 & $\begin{array}{l}\text { É preciso recuperar as médias salariais no magistério, para que a carreira volte } \\
\text { a atrair os melhores profissionais. }\end{array}$ \\
\hline $\mathrm{T} 12$ & $\begin{array}{l}\text { O governador Serra defende que o projeto cria um estímulo aos professores } \\
\text { da rede, além de atrair jovens mais bem preparados para o magistério. }\end{array}$ \\
\hline T13 & $\begin{array}{l}\text { A valorização é crucial para que a profissão se torne mais atrativa entre } \\
\text { os formandos com bom desempenho nas faculdades. }\end{array}$ \\
\hline T14 & $\begin{array}{l}\text { Isso porque os formados em física acabam atraídos por outras profissões com } \\
\text { maior retorno financeiro }\end{array}$ \\
\hline
\end{tabular}

Ao ler os fragmentos acima, observa-se que o encadeamento de ideias é tão grande que até pode parecer, ao leitor desavisado, um único texto sem os devidos conectivos. Isso demonstra que foi pertinente nossa decisão de olhar para as matérias na perspectiva do encadeamento de sentidos. 
Em síntese, a partir dos trabalhos apresentados observamos que ainda que as perspectivas metodológicas se diferenciem elas apontam que o lugar e o modo de falar do professor no jornalismo, em revistas ou em jornais, permanece numa perspectiva de conformação de uma imagem pejorativa do professor e deve ser constantemente contestado.

\section{CONCLUSÕES}

Ao longo deste artigo, buscamos responder a indagação que fundamentou nossa tese: quando o professor é notícia? Para tanto, analisamos notícias relacionadas ao trabalho do professor, publicadas entre janeiro de 2009 e janeiro de 2010 no jornal Folha de S.Paulo, buscando depreender as imagens que os jornalistas se colam ao escrever sobre o professor.

A tese foi construída a partir da seguinte hipótese: sendo o jornalista um sujeito afetado pelo inconsciente ${ }^{12}$, o texto objetivo nada mais é que uma construção ideológica que se organiza por meio de Formações Imaginárias e Ideológicas e serve para: 1) silenciar a presença do inconsciente na escrita jornalística; 2) construir imagens fragmentadas sobre o jornalismo e o professor; e 3) apagar a presença das identificações de que o sujeito se vale para construir tais imagens.

Para confirmar essa hipótese, colocamo-nos alguns enfrentamentos, desmembrados em quatro etapas: 1) recuperação das relações entre jornalismo e linguagem; 2) problematização do uso das fontes no jornalismo; 3) definição do conceito de notícia; e 4) análise de quais são e dos modos como o jornalismo constrói as imagens sobre os professores.

Tendo como referência teórica o trabalho de Pêcheux sobre as Formações Imaginárias e Ideológicas, defendemos que ainda que no texto jornalístico se tente apagar a inscrição discursiva, ele é, antes de tudo, uma produção de sentidos sobre o mundo. Assim, constatamos que o modo de o jornalismo falar sobre os professores se dá num processo de jogos de imagens, em que a perspectiva negativa do professor se dá sempre em contraponto a uma imagem positiva do jornalismo.

A análise dos textos nos mostrou que um dos recursos utilizados pelo jornalismo para produzir uma imagem positiva de si é o apoio num "pseudo" discurso de cientificidade, que reforça a perspectiva de que seus discursos são representações objetivas da realidade. Em contrapartida, outra conclusão a que chegamos foi que a imagem dos professores continua se constituindo sob uma perspectiva negativa, acrescida de um dado novo que é a crescente proposição de exclusão dos professores e substituição desses profissionais por outros melhores como saída para os problemas da educação.

Observamos que um dos recursos que acabam por contribuir com o desenvolvimento de tais imagens é o uso do conceito de objetividade que prende o jornalista em duas inversões ideológicas, a primeira a de que ele seria responsável pelo dizer e outra a de que o dito por ele representa a realidade.
12. FREUD, Sigmund. Conferências introdutórias sobre psicanálise. (1916-1917). São Paulo: Companhia das Letras, 2014. 
Para construir um texto que sustente tais inversões, o jornalista recorre a dados mensuráveis e prende-se ao uso da voz do outro para se sustentar.

Observamos, a partir das análises, que não é exatamente uma novidade falar em imagens e representações negativas do professor no jornal, porém, procuramos problematizar tal produção jornalística e apontar como poderíamos contribuir para tal produção. Entendemos que a pertinência de nosso trabalho não é constatar a manutenção de um discurso pejorativo, acrescido de novos elementos, mas apontar que os sentidos negativos só se materializam graças aos jogos de imagens que permitem a construção de textos a partir de sentidos positivos do jornalismo.

\section{REFERÊNCIAS BIBLIOGRÁFICAS}

ANJOS, Cleriston Izidro dos. A educação infantil representada: uma análise da revista Nova Escola (2005-2007). Dissertação de mestrado. Faculdade de Educação, Universidade de São Paulo, 2008.

BARBARA, L.; BERBER-SARDINHA, T. Professor: A imagem projetada na imprensa. Ilha do Desterro. (UFSG), v. 17, n. 2, 2004.

BARZOTTO, V. H. Olhares oblíquos sobre sentidos não muito dissimulados. In: GREGOLIN, Maria do Rosário; BARONAS, Roberto (org.). Análise do Discurso: as materialidades do sentido. São Carlos: Claraluz, 2001.

Leituras de revistas periódicas: forma, texto e discurso. Uma leitura da revista Realidade (1966-1976). Tese de doutorado. Campinas, Unicamp, 1998.

CARMAGNANI, A. M. G. Técnicas de Vigilância e Punição: O discurso da mídia sobre o professor e a escola. Verso \& Reverso. Rio Grande do Sul, v. 2, n. 39, 2004.

FERREIRA, R. Entre o sagrado e o profano: o lugar social do professor. Rio de Janeiro: Quartet, 2002.

FREUD, Sigmund. Conferências introdutórias sobre psicanálise. São Paulo: Companhia das Letras, 2014.

PÊCHEUX, Michel. Semântica e Discurso. Uma crítica à afirmação do óbvio. Campinas: Ed. da Unicamp, 2009.

; FUCHS, C. A propósito da análise automática do discurso: atualização e perspectivas. In: GADET, Françoise; HAK, Tony. Por uma análise automática do discurso: Uma introdução à obra de Michel Pêcheux. Campinas: Editora da Unicamp, 2010.

A Análise do Discurso: três épocas. In: GADET, F.; HAK. T.

Por uma Análise Automática do Discurso. Uma introdução à obra de Michel Pêcheux. Campinas: Ed. da Unicamp, 1997. 
ROCHA, Andreza Roberta. Relatos de experiência publicados na revista Nova Escola (2001-2004): modelo de professora ideal. Dissertação de mestrado. Faculdade de Educação, Universidade de São Paulo, 2007.

\section{RELAÇÃO DE MATERIAL JORNALÍSTICO CONSULTADO}

\section{1 - Matérias da Folha de S.Paulo}

FOLHA. Critérios de correção da redação são subjetivos. Análise de Carlos Eduardo Bindi. 08/01/2012. Disponível em: <http://acervo.folha.com.br/ fsp/2012/01/08/15/5741586>. Acesso em: 10 jan. 2012.

FOLHA. Capa da Folha de São Paulo. 22/05/2011. Folha de São Paulo, 2011 a.

FOLHA. Circulação: o maior jornal brasileiro. Informações disponíveis em: $<$ www1.folha.uol.com.br/folha/conheca/circulacao.shtml $>$. Folha de São Paulo, 2011b. Acesso em: 16 dez. 2011.

FOLHA. Ouça trecho em que Emir Sader chama Ana Hollanda de meio autista. Disponível em: <www1.folha.uol.com.br/ilustrissima/882706-oucatrecho-em-que-emir-sader-chama-ana-de-hollanda-de-meio-autista.shtml>. Folha de São Paulo: 2011c. Acesso em: jan. 2012.

FOLHA. País forma cada vez menos professores. 03/02/2009. Folha de São Paulo, 2009a.

FOLHA. Para pedagogos, baixo salário e desprestígio explicam o fenômeno. 03/02/2009. Folha de São Paulo, 2009b.

FOLHA. Congresso aprova aumento de verba para educação. 12/11/2009. Folha de São Paulo, 2009c.

FOLHA. Inclusão digital ainda não é realidade na sala de aula. 15/11/2009. Folha de São Paulo em Ribeirão Preto, 2009d.

FOLHA. O que funciona na educação: as lições segundo a McKinsey. 28/10/2007. Folha de São Paulo, 2007.

FOLHA. Carreira de professor atrai menos preparados. 09/06/2008 Folha de São Paulo, 2008a.

FOLHA. A volta da Filosofia. Disponível em: <www1.folha.uol.com.br/folha/ pensata/helioschwartsman/ult510u411269.shtml> Acesso em: 16 jan. 2011. 12/06/2008. Folha de São Paulo: 2008b.

FOLHA, S.P. O maior jornal brasileiro. Disponível em: <www1.folha.uol.com. $\mathrm{br} /$ folha/conheca/circulacao.shtml>. Acesso em: $16 \mathrm{dez} .2010$. 